INTERNATIONAL JOURNAL OF MULTIDISCIPLINARY RESEARCh AND ANALySis

ISSN(print): 2643-9840, ISSN(online): 2643-9875

Volume 04 Issue 10 October 2021

DOI: 10.47191/ijmra/v4-i10-23, Impact Factor: 6.072

Page No.- $1485-1491$

\title{
Users' Satisfaction to Medical Examination and Treatment Services with Health Insurance Cards In NINH BINH Province, Vietnam
}

\author{
Nguyen Zen Nguyen ${ }^{1}$, Thi Huu Ai Nguyen ${ }^{2}$, Thi Xuan Huong Le ${ }^{3}$, Thi Huong Tram Le ${ }^{4}$
}

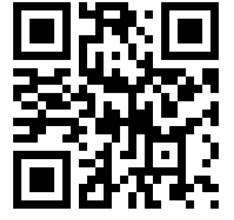

SUMMARY: Health insurance is an important social policy with humanitarian meaning and profound community sharing, which is highly valued and promoted by the Vietnamese Government in the social security policy system. Therefore, it is necessary to study users' satisfaction to medical examination and treatment services with health insurance cards. Based on the questionnaire surveys, the research team conducted Cronbach's Alpha analysis of each factor, assessed the scale reliability. Multivariate regression and ANOVA test showed that all four components: health services, human resources, medical examination and treatment costs, medical information and medical products positively affected users' satisfaction to medical examination and treatment services with health insurance cards in Ninh Binh province, Vietnam. Based on the survey results and the information exchanged directly with people who came for medical examination and treatment, the research team drew out shortcomings in medical examination and treatment for users of health insurance card sin Ninh Binh province. Shortcomings in medical examination and treatment with health insurance cards were pointed out as an important basis for proposals to improve the medical examination and treatment quality for insured subjects including: Health insurance costs and response levels; Medical examination and treatment process with health insurance and doctor's responsibility. Reasonable waiting time and hospital environment; Health insurance-based drug delivery.

KEYWORDS: HIC; Medical examination and treatment; Satisfaction; Vietnam

\section{PREAMBLE}

Health insurance-based medical examination and treatment quality is the relationship between the demand and the ability to meet the demand for medical examination and treatment with health insurance card. Disease treatment when using health insurance cards is actually medical service. Health insurance-based medical examination and treatment quality is constituted by a series of related factors such as administrative procedures for medical examination and treatment; professional qualifications, spirit, attitude, and professional ethics of doctors and medical staff and quality material conditions that satisfy health insurance card holders. Improving medical examination and treatment service quality for users of health insurance cards in order to better meet their needs and aspirations will create health insurance sustainability. Currently, Ninh Binh province is home to a large number of patients receiving medical examination and treatment with health insurance at the provincial and district levels, both in terms of initial registration for medical examination and treatment and receiving referral patients. The study of users' satisfaction to medical examination and treatment services with health insurance cards in Ninh Binh Province, Vietnam is very necessary and has practical significance. So, subjects of medical examination and treatment with health insurance cards are satisfied with the health insurance-based medical examination and treatment quality? What causes affect the health insurancebased medical examination and treatment quality in Ninh Binh province?

\section{THEORETICAL BASIS AND RESEARCH MODEL}

\subsection{Some concepts}

Health insurance is a form of insurance applied in the field of health care, not for profit, organized by the State and the responsible participants in accordance with the provisions of the Law [8].

\footnotetext{
${ }^{1}$ University of Labour and Social Affairs

${ }^{2}$ University of Labour and Social Affairs

${ }^{3}$ University of Labour and Social Affairs

${ }^{4}$ University of Labour and Social Affairs
} 


\section{Users' Satisfaction to Medical Examination and Treatment Services with Health Insurance Cards In NINH BINH}

Province, Vietnam

Service quality, definition and measurement of service largely originate in the field of goods production. Parasuraman, Zeithaml \& Berry (1985) supposed that perceived service quality is a comparison between customer expectations and supplier's service performance, and service quality assessment is not based solely on service performance outcomes, which must include the performance process [9].

Regarding satisfaction, there are many different views on levels of satisfaction - customer satisfaction. Bachelet (1995) supposed that customer satisfaction is the feedback of consumers, which are comments about characteristics of a product or service or the product or service itself. These feedbacks will show different levels of satisfaction when they consume a product and service [1].

Relationship between service quality and satisfaction. According to Zeithaml and Bitner (2000), service quality and customer satisfaction are two different concepts, while service quality focuses specifically on the service components, customer satisfaction is a general concept [15]. Thus, service quality is a factor that greatly affects customer satisfaction. If a service provider provides customers with quality products that satisfy their needs, that provider has initially made customers happy.

\subsection{Theoretical background}

Gronroos's service quality measurement model, service quality is considered based on two criteria, Functional Service Quality (FSQ) and Technical Service Quality (TSQ). Moreover, service quality is strongly influenced by corporate image [2].

SERVQUAL service quality and customer satisfaction model that took theoretical ideas from tGronroos (1984), Parasuraman (1985) models built a mixed measurement tool, called SERVQUAL, used to measure perceived service quality, the SERVQUAL scale set contains 22 pairs of Likert scale items to separately measure customers' actual expectations and perceptions of service quality [9].

WHO research model of satisfaction in health sector. Medical service is a special type of service. WHO believes that a good health system needs to combine relevant functional parts, which are: provided services; medical human resources; medical information; medical products such as drugs, vaccines, equipment, technology; health financing system; leadership and management [14].

Based on the 10-component model theory, assessing customer satisfaction using Parasuraman's service and the theoretical basis of the criteria for evaluating WHO's health system quality, the research team drew out the following model:

Figure 1.1. Model to assess the satisfaction of medical examination and treatment subjects with health insurance cards

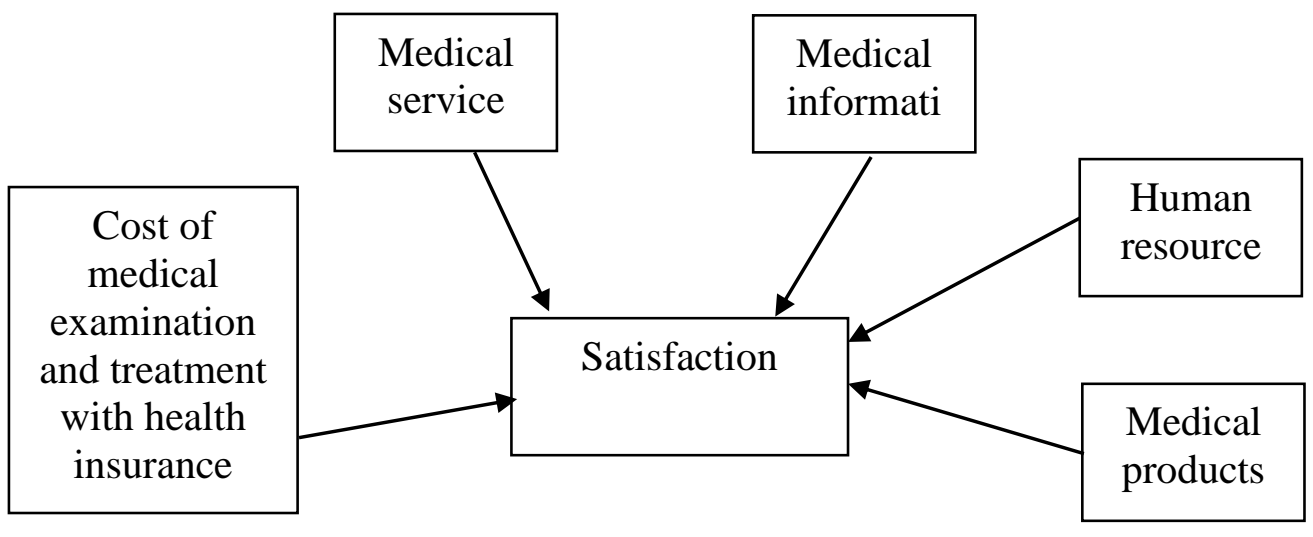

Source: Construction research team

\subsection{Research hypotheses}

Quality medical services require hospital timeliness of services both in terms of time and needs of patients with health insurance cards. For example, clean hospital beds, modern facilities, cool spaces, professional staff. Hypothesis H1: The provided medical services affect health insurance-based patient's satisfaction in Ninh Binh province, Vietnam.

Medical information is the keeping in touch with patients and their family such as medical examination and treatment situation. Hypothesis H2: Medical information in the hospital's medical examination and treatment affects health insurancebased patient's satisfaction in Ninh Binh province, Vietnam. 


\section{Users' Satisfaction to Medical Examination and Treatment Services with Health Insurance Cards In NINH BINH}

Province, Vietnam

A qualified human resources team is a way that medical staff guarantees efficient, continuous, and fair provision of medical services, demonstrated by patient care, responsiveness and satisfaction to their needs. Hypothesis H3: Hospital human resources affect health insurance-based patient's satisfaction in Ninh Binh province, Vietnam.

Medical products such as drugs, vaccines, equipment, and technology are provided safely, with quality, scientifically and effectively. Hypothesis H4: Medical products have an impact on health insurance-based patient's satisfaction in Ninh Binh province, Vietnam.

Health insurance costs are effective in determining treatment costs. The cost of medical examination and treatment should be equitable, ensuring provision of the same health care services to all patients under different living conditions. Hypothesis H5: health insurance-based medical examination and treatment affects health insurance-based patient's satisfaction in Ninh Binh province, Vietnam.

\section{RESEARCH METHODS}

\subsection{Qualitative research}

Document research: Collect and research relevant research works that have been carried out at home and abroad to draw and develop the theoretical basis for the topic.

Descriptive statistics: Primary and secondary information are used to make an assessment and primary and secondary data system on the real quality of medical examination and treatment for subjects using health insurance cards in the Ninh Binh province.

\subsection{Quantitative research}

The survey samples were taken by convenience method. The sample size taken depends on the analytical method, this study uses descriptive statistics and some tests, so the sample size was at least 5 times the observatory variable [11]. Therefore, with 220 questionnaires distributed during the survey in Ninh Binh province, the research team collected 197 votes, 19 of which were invalid, the remaining 178 votes were input and data analyzed sufficiently to analytical methods in the study with 21 component variables. The topic uses SPSS 22.0 software to support the analysis of primary data collected through pre-prepared questionnaires. With the primary data collected, the author used descriptive statistics method with criteria such as frequency, rate, and mean to analyze the actual situation on use of medical services by health insurance card users in Ninh Binh province. Simultaneously, groups of factors affecting the satisfaction of health insurance patients in Ninh Binh province were analyzed by Cronbach's Alpha factor in combination with exploratory factor analysis (EFA). The author applied multivariate linear regression analysis model to review the impact of groups of factors on patient satisfaction.

\subsection{Research scale}

The proposed research model includes 5 criteria, using a 5-point liket scale with observatory variables whose content and symbols are presented in Table 3.1.

Table 3.1. Detailed explanation of variables in the model

\begin{tabular}{|c|c|c|}
\hline Factor & Sign & Observable variable content \\
\hline \multirow{6}{*}{$\begin{array}{l}\text { Medical service } \\
\text { (MS) }\end{array}$} & MS1 & Doctors got to work as soon as they are requested \\
\hline & MS2 & $\begin{array}{l}\text { Procedures for medical examination and treatment with health insurance are } \\
\text { carried out quickly }\end{array}$ \\
\hline & MS3 & Waiting time for medical examination and treatment is reasonable \\
\hline & MS4 & $\begin{array}{l}\text { Doctors and nurses always advise patients on how to take care of their health } \\
\text { and use medicines when they leave the hospital }\end{array}$ \\
\hline & MS5 & The hospital environment is always clean \\
\hline & MS6 & Waiting chairs are enough to meet the patient's request \\
\hline \multirow{3}{*}{$\begin{array}{l}\text { Medical information } \\
\qquad \text { (MI) }\end{array}$} & MI1 & $\begin{array}{l}\text { Medical teams, doctors always clearly inform the treatment situation to } \\
\text { patients/patient's family promptly and quickly. }\end{array}$ \\
\hline & MI2 & Information about the patient's health is provided in full \\
\hline & MI3 & $\begin{array}{l}\text { Patients are well informed of procedures related to medical examination and } \\
\text { treatment with health insurance cards }\end{array}$ \\
\hline Human resource & HR1 & Doctors and nurses respond to patients' needs in a dedicated and thoughtful \\
\hline
\end{tabular}


Users' Satisfaction to Medical Examination and Treatment Services with Health Insurance Cards In NINH BINH Province, Vietnam

\begin{tabular}{|c|c|c|}
\hline \multirow[t]{5}{*}{ (HR) } & & manner \\
\hline & HR2 & $\begin{array}{l}\text { Doctors and nurses are always concerned about patient's health and medical } \\
\text { condition }\end{array}$ \\
\hline & HR3 & Medical staff, doctors are trusted by patients \\
\hline & HR4 & Doctors and nurses are well experienced in medical examination and treatment \\
\hline & HR5 & $\begin{array}{l}\text { Medical teams and doctors do not discriminate between patients receiving } \\
\text { medical examination and treatment with health insurance cards and other } \\
\text { subjects }\end{array}$ \\
\hline \multirow{3}{*}{$\begin{array}{l}\text { Medical products } \\
\qquad(\mathrm{MP})\end{array}$} & MP1 & The hospital has modern equipment and technology \\
\hline & MP2 & $\begin{array}{l}\text { Medicines for medical examination and treatment with health insurance are } \\
\text { prescribed clearly and specifically }\end{array}$ \\
\hline & MP3 & Hospital facilities responds well to the treatment \\
\hline \multirow{4}{*}{$\begin{array}{l}\text { Cost of medical examination } \\
\text { and treatment with health } \\
\text { insurance } \\
\text { (CTHI) }\end{array}$} & CTHI1 & Cashiers clearly explains hospital bills to patients \\
\hline & CTHI2 & Hospital bill is presented clearly, easy to understand \\
\hline & CTHI3 & $\begin{array}{l}\text { The co-payments of patients with health insurance are included in the hospital } \\
\text { fees at the prescribed rate }\end{array}$ \\
\hline & CTHI4 & Health insurance costs are paid on basis of services patients are provided \\
\hline \multirow{3}{*}{$\begin{array}{l}\text { Satisfaction } \\
\qquad \text { (SF) }\end{array}$} & SF1 & $\begin{array}{l}\text { Are you satisfied with the hospital fees spent during medical examination and } \\
\text { treatment }\end{array}$ \\
\hline & SF2 & Are you satisfied with your medical examination and treatment at the hospital \\
\hline & SF3 & Do you return to the hospital for follow-up visits? \\
\hline
\end{tabular}

Source: Construction research team

\section{RESEARCH RESULTS}

\subsection{Situation of medical examination and treatment with health insurance cards in Ninh Binh province}

From the table summarizing turns of people who receive medical examination and treatment with health insurance cards in Ninh Binh province, the number of people who receive medical examination and treatment with health insurance cards in Ninh Binh province has increased over years. Especially from 2018 the number of people coming for medical examination with health insurance cards increased by $123 \%$ compared to 2017[4]. This is partly because inter-route medical examination and treatment regulations became effective, in addition to well-performed medical examination and treatment for people using health insurance cards, the number of visits for this type of medical examination and treatment increases year by year. In the first 6 months of 2020, Ninh Binh province received 171,000 people who came for medical examination and treatment; including nearly 120,000 turns with health insurance cards [5]. According to hospital assessment, the number of people who came for medical examination and treatment people decreased sharply in the first 6 months of the year by the influence of the Wuhan pneumonia pandemic

\subsection{Users' satisfaction to medical examination and treatment services with health insurance cards in Ninh Binh province}

\subsubsection{Analyzing scales by coefficient}

When analyzing scales by Cronbach's alpha reliability coefficient, we can eliminate the observatory variables that are not suitable for the research and at the same time it limits the variables that are not useful to the topic, making it difficult to determine the variability and identify errors in the variables. They are considered garbage variables and will be removed in subsequent analysis steps. The Cronbach's Alpha coefficient must be greater than 0.6 but preferably $0.7[11]$.

Table 4.1. Scale reliability coefficient testing results

\begin{tabular}{|c|c|c|c|c|c|}
\hline Scale & $\begin{array}{c}\text { Initial observed } \\
\text { variable }\end{array}$ & Cronbach's Alpha & $\begin{array}{c}\text { Corrected Item- } \\
\text { Total Correlation }\end{array}$ & $\begin{array}{c}\text { Cronbach's Alpha if } \\
\text { Item Deleted }\end{array}$ & $\begin{array}{c}\text { Remaining } \\
\text { observed variable }\end{array}$ \\
\hline MS & 6 & .902 & .669 & .895 & 6 \\
\hline MI & 3 & .921 & .803 & .915 & 3 \\
\hline HR & 5 & .888 & .662 & .879 & 5 \\
\hline MP & 3 & .754 & .552 & .704 & 3 \\
\hline
\end{tabular}


Users' Satisfaction to Medical Examination and Treatment Services with Health Insurance Cards In NINH BINH Province, Vietnam

\begin{tabular}{|c|l|l|l|l|l|}
\hline $\mathrm{CTHI}$ & 4 & .868 & .687 & .843 & 4 \\
\hline $\mathrm{SF}$ & 3 & .818 & .647 & .736 & 3 \\
\hline
\end{tabular}

Source: Survey data processing results

It can be seen that the minimum total variable component correlation of the scales is $>0.5$ in accordance with the research purpose and novelty of the topic. In particular, the reliability coefficients are still quite good with most of the levels greater than 0.8 and the lowest was also 0.754 . This shows good scales and reliability for future research and analysis.

\subsubsection{Exploratory factor analysis}

Kaiser - Mayer - Olkin index will evaluate the suitability of EFA analysis, $0.5 \leq \mathrm{KMO} \leq 1$. Large KMO value means factor analysis is appropriate. If this is statistically significant (Sig. $<0.05$ ), the observatory variables are correlated with each other in the population. Percentage of variance $>50 \%$ : shows the percentage variation of the observatory variables. That is, considering the variation is $100 \%$, this value shows how much $\%$ can be explained by the factor analysis [11].

Table 4.2. Synthesized results of exploratory factor analysis (EFA) for each scale

\begin{tabular}{|c|c|c|c|c|c|}
\hline Scale & KMO coefficient & Sig & $\begin{array}{l}\text { Total variance } \\
\text { explained }\end{array}$ & $\begin{array}{l}\text { Number of factors } \\
\text { eliminated }\end{array}$ & $\begin{array}{l}\text { Number } \\
\text { converging } \\
\text { factors }\end{array}$ \\
\hline MS & .869 & 0.000 & 67.273 & 0 & 1 \\
\hline MI & .749 & 0.000 & 86.382 & 0 & 1 \\
\hline HR & .816 & 0.000 & 69.180 & 0 & 1 \\
\hline MP & .688 & 0.000 & 67.008 & 0 & 1 \\
\hline CTHI & .817 & 0.000 & 71.608 & 0 & 1 \\
\hline
\end{tabular}

Source: Survey data processing results

The results shown on the factor rotation matrix show us that 21 observatory variables converge on 5 factors including the group of factors about health services, medical information, human resources, and medical products, and the cost of medical examination and treatment with the factor weights 0.5 .

The EFA exploratory factor analysis for the dependent variable scale also needs to comply with the same regulations as the independent variable scales. EFA results show that all 3 observatory variables of satisfaction scale explain $73.311 \%$, all converge on only 1 common factor, with all factor weights 0.5 . Therefore, all three observatory variables are kept for the next analysis step.

\subsubsection{Regression analysis}

After performing EFA analysis to test the convergent validity and discriminant validity of the scales, we will test the hypotheses proposed in the research model.

The regression equation to be performed is multivariate regression equation, to determine the important role of each component in assessing the relationship between satisfaction and aforementioned components of scales.

The results of the linear regression analysis are as follows:

Table 4.3. Linear regression results

\begin{tabular}{|c|c|c|c|c|c|c|c|c|c|}
\hline \multirow[b]{2}{*}{ Model } & \multirow[b]{2}{*}{$\mathbf{R}$} & \multirow[b]{2}{*}{ R Square } & \multirow[b]{2}{*}{ Adjusted R Square } & \multirow{2}{*}{$\begin{array}{l}\text { Std. Error of the } \\
\text { Estimate }\end{array}$} & \multicolumn{5}{|c|}{ Change Statistics } \\
\hline & & & & & R Square Change & F Change & f1 & f2 & Sig. F Change \\
\hline 1 & $.683^{a}$ & .467 & .451 & .66074 & .467 & 30.134 & 5 & 172 & .000 \\
\hline
\end{tabular}

a. Predictors: (Constant), MS, MI, HR, MP, CTHI

b. Dependent Variable: SF

Source: Survey data processing results

We see that adjusted $\mathrm{R}$ square $=.551(>0.5)$ indicates that 5 components have an influence on the users' satisfaction to medical examination and treatment services with health insurance cards. Thus, the model suitability is relatively high. Looking at this regression analysis result, we see that the preconditions for regression analysis are satisfied. Thus, we can consider the regression analysis result reliable. However, this is only true for the sample data. To test whether the model can be deduced for the real population, we must test the model's suitability: 
Users' Satisfaction to Medical Examination and Treatment Services with Health Insurance Cards In NINH BINH Province, Vietnam

Hypothesize

Ho: MS, MI, HR, MP, CTHI and SF have a relationship

$\mathrm{H} 1: \mathrm{MS}, \mathrm{MI}, \mathrm{HR}, \mathrm{MP}, \mathrm{CTHI}$ and $\mathrm{SF}$ have no relation to each other

Choose significance level $=0.05$ corresponding to $95 \%$ level

Table 4.4: ANOVA testing

\begin{tabular}{|c|c|c|c|c|c|c|}
\hline \multicolumn{2}{|c|}{ Model } & Sum of Squares & df & Mean Square & F & Sig. \\
\hline \multirow{3}{*}{1} & Regression & 65.778 & 5 & 13.156 & 30.134 & $.000^{\mathrm{b}}$ \\
\cline { 2 - 7 } & Residual & 75.090 & 172 & .437 & & \\
\cline { 2 - 8 } & Total & 140.869 & 177 & & & \\
\hline
\end{tabular}

a. Dependent Variable: SF

Source: Survey data processing results

The ANOVA test result shows that the F-test value is 30.134 at the significance sig $=0.000<\alpha=0.1$. Thus, we reject hypothesis $\mathrm{HO}$, accept hypothesis $\mathrm{H} 1$, that is, 4 components of independent variables MS, MI, HR, MP, CTHI and SF relate with each other. Therefore, the model fits the data set and can be generalized to the population.

Check for multicollinearity: Tolerance or variance inflation factor (VIF) are used. Regarding the VIF value, VIF exceeding 10 is a sign of multicollinearity [11].

Table 4.5: Results of multivariate regression model

\begin{tabular}{|c|c|c|c|c|c|c|c|c|c|c|c|}
\hline \multirow{2}{*}{\multicolumn{2}{|c|}{ Model }} & \multicolumn{2}{|c|}{$\begin{array}{l}\text { Unstandardized } \\
\text { Coefficients }\end{array}$} & \multirow{2}{*}{$\begin{array}{c}\text { Standardized } \\
\text { Coefficients } \\
\text { Beta }\end{array}$} & \multirow[b]{2}{*}{$\mathbf{t}$} & \multirow[b]{2}{*}{ Sig. } & \multicolumn{3}{|c|}{ Correlations } & \multicolumn{2}{|c|}{ Collinearity Statistics } \\
\hline & & B & Std. Error & & & & $\begin{array}{l}\text { Zero- } \\
\text { order }\end{array}$ & Partial & Part & Tolerance & VIF \\
\hline \multirow[t]{6}{*}{1} & (Constant) & .339 & .243 & & 1.392 & .166 & & & & & \\
\hline & SPYT & .136 & .069 & .131 & 1.986 & .049 & .432 & .150 & .111 & .713 & 1.403 \\
\hline & DVYT & .300 & .079 & .271 & 3.788 & .000 & .565 & .277 & .211 & .605 & 1.653 \\
\hline & DNNL & .183 & .073 & .191 & 2.519 & .013 & .555 & .189 & .140 & .542 & 1.846 \\
\hline & CPKCB & .149 & .067 & .157 & 2.205 & .029 & .503 & .166 & .123 & .612 & 1.634 \\
\hline & TTYT & .124 & .051 & .157 & 2.399 & .017 & .462 & .180 & .134 & .724 & 1.382 \\
\hline
\end{tabular}

a. Dependent Variable: SF

Source: Survey data processing results

The regression table shows that the regression coefficients of the factors all are positive and $R=.683 a>0$ (Table 4.5), that means, these components have a directly proportional impact on customer satisfaction to medical examination and treatment with health insurance cards. Thus, the accepted hypothesis of the research model means that the components of health service, human resource, medical examination and treatment cost, medical information and medical products have a positive relationship with users' satisfaction to medical examination and treatment services with health insurance cards in Ninh Binh province. At the same time, the regression table also shows that the variance exaggeration factor VIF $<2$, proving that the problem of multicollinearity does not appear in this study.

\section{DISCUSSION OF RESEARCH RESULTS}

Assessing the importance of factors affecting users' satisfaction to medical examination and treatment services with health insurance cards in Ninh Binh province. The regression table (4.5) allows us to test the regression coefficients in the model. Components with statistical significance less than $5 \%$ are kept, and components with statistical significance greater than $5 \%$ are discarded. The larger the beta coefficient of any component is, the more important it is, showing the influence on the dependent variable, the regression analysis table show that the constant is not statistically significant because constant sig = $0.166>0.05$, so the constant does not affect the regression equation we mentioned above. The remaining 5 factors are all relevant and have a positive influence on SATISFACTION. Specifically, the health service has the strongest influence with a Beta coefficient of 0.271 ( $t=3.788$ and Sig < 0.05), followed by human resources with a Beta coefficient of 0.191 ( $t=2.519$ and Sig < 


\section{Users' Satisfaction to Medical Examination and Treatment Services with Health Insurance Cards In NINH BINH Province, Vietnam}

$0.05)$ as the second largest influence. In third place are two components health information and medical examination and treatment costs with a Beta coefficient of 0.157 ( $t=2.205$ and Sig < 0.05). Finally, the medical products with a Beta coefficient of 0.131 ( $\mathrm{t}=1.986$ and $\mathrm{Sig}<0.05$ ) is also the component that has the lowest influence on users' satisfaction to medical examination and treatment services with health insurance cards in Ninh Binh province.

Based on the survey results and the external exchange information with the patients who come for medical examination and treatment, the research team has drawn the shortcomings in medical examination and treatment for users of health insurance cards in Ninh Binh province. The analysis of factor models affecting the health insurance holder's satisfaction to medical examination and treatment services at Ninh Binh Provincial General Hospital shows that patient satisfaction was affected by 5 groups of factors: health insurance-based medical examination and treatment costs and level of response; health insurance-based medical examination and treatment procedures and doctor's responsibility; reasonable waiting time and hospital environment; health insurance drug delivery. Although these groups of factors were rated above average by patients, in fact, through sharing and opinions from patients participating in health insurance who have been examined and treated at Ninh Binh provincial hospital, it is found that there are still difficulties and shortcomings.

\section{REFERENCES}

1) Bachelet, D. (1995), Measuring Satisfaction, or the Chain, the Tree and the Nest in Brooks

2) Gronroos, C. (1984), A service quality model and its marketing implication, European Journal of Marketing,

3) Hair. J.Black, W. Babin, and Anderson, R. (2010), Multivariate data analysis (7th ed). Prentice Itall, Inc. Upper saddle River, NJ, USA

4) Health service Dept (2018), Summary report on health performance in 2017 and orientations, key tasks in 2018, Ninh Binh, Vietnam

5) Health service Dept (2020), Summary report on health performance in 2020 and orientations, key tasks in 2021, Ninh Binh, Vietnam

6) http://www.benhvienninhbinh.vn/trang-chu

7) Ministry of Health (2008), Health economics and insurance, Medicine Publishing House, Hanoi

8) National Assembly (2008), Health Insurance Law, National Assembly, Vietnam

9) Parasuraman, A., Zeithaml, V.A., Berry, L.L. (1985), A conceptual model of service quality and its implications for future research, Journal of Marketing.

10) Richard Ed. (1995), Customer Satisfaction Research, Amsterdam, European Society for Opinion and Marketing Research.

11) Trong, H \& Ngọc, C.N.M (2008), Data Analysis with SPSS, Hong Duc Publishing House.

12) Victor Sower \& ctg, (2001), The dimensions of services quality for hospitals: Development and use of KQCAH Scale, Heath care manage rev, Aspen publishere,Inc

13) Vietnam Association of Health Economic Sciences (2010), Theoretical Framework for Renovating and Improving the Health System, Ministry of Health, Hanoi

14) WHO (2007), Everybody's business: strengthening health systems to improve health outcomes, WHO

15) Zeithaml \& Bitner (2000), Services marketing: intergrating customer focus across the firm. 2nd Edition, McGraw-Hill, Boston. 